\title{
Strengthening of Inner Wall of N80 Oil Tubing Induced by Laser Surface Melting Spirally
}

\author{
Lixin Song ${ }^{1, a}$, Meiyan $\mathrm{Li}^{2, b^{*}}$ \\ ${ }^{1}$ Offshore Oil Engineering (Qingdao) Co., Ltd., Qingdao 266520, China \\ ${ }^{2}$ College of Electromechanical Engineering, China University of Petroleum, Qingdao, 266580, \\ China \\ asonglx@mail.cooec.com.cn, ${ }^{b}$ Imy_102411@163.com
}

\begin{abstract}
Keywords: N80; Inner Wall; LSM; Spiral Machining; Strengthening
Abstract. Laser surface melting(LSM) was performed on the inner wall of N80 oil tubing by the spiral mode. The results show that the microstructure of N80 oil tubing consists of zonal pearlite and ferrite. After LSM, the cross section was divided into the melted zone composed of martensite transformation hardening zone, high temperature tempering zone and the matrix. The microhardness was improved significantly, while the maximum appeared in the transformation hardening zone. The uneven wear phenomenon occurred on the inner wall of the N80 oil tubing, and a lot of plough and obvious spalling appeared. In addition, the wear resistance of the laser melted N80 oil tubing was improved obviously, especially the wear resistance of the melted sample with small pitch is higher than the large pitch. The plastic deformation stopped at the interface of the melted zone and the untreated zone, and the wear scars are shallow.
\end{abstract}

\section{Introduction}

The friction and wear problem between the tubing and the coupling is a hot issue, which hinders the production of oil well [1]. The relative motion of the sucker rod and the oil tubing belongs to the reciprocating movement occurred in the stroke range. The movement speed is usually lower than $1 \mathrm{~m} / \mathrm{s}$, which belongs to low speed motion. If the lubricating condition between the friction pairs is poor, serious wear phenomenon will be caused. Especially the wear problems are very complicated affected by wellbore structure, working system and the nature of drilling fluid. The serious wear phenomenon will result in the replacement of the oil tubing frequently, which will increase the production cost [2].

In order to minimize economic losses and to conserve expensive materials, products with enhanced surface properties are expected. In recent years, advanced rapid solidification technologies such as surface melting employing laser-beam [3, 4], electron-beam [5] and ion-beam [6, 7] have been reported to be feasible routes for enhancing the surface properties and have gained increasing technological interest. Among these surfacing techniques, laser surface melting (LSM) is the simplest and most economical treatment method. It does not involve change in the overall chemical compositions and no additional precious materials are needed. LSM has been reported to be an effective method to enhance the properties $[8,9]$. However, few studies are related to the effect of LSM on the inner wall of N80 oil tubing by the spiral mode. In this paper, the inner light-guide system was applied to strengthen the inner wall of N80 oil tubing by the spiral machining method. The microstructure and wear resistance were analysed.

\section{Experimental Method}

The as-received oil tubing is N80 steel, and the chemical composition is shown in Table 1. The dimension of the sample is $\Phi 76 \mathrm{~mm} \times 6.5 \mathrm{~mm}$, and the length is $100 \mathrm{~mm}$. LSM was carried out by a $5 \mathrm{~kW}$ continuous wave $\mathrm{CO}_{2}$ laser with a power of $1000 \mathrm{~W}$. A traverse speed of $3850 \mathrm{~mm} / \mathrm{min}$ was applied during laser melting. The pitch of $6 \mathrm{~mm}$ and $12 \mathrm{~mm}$ was applied (As shown in Fig. 1), and the laser beam with a Gaussian energy density distribution was defocused on the surface to a spot of $3 \mathrm{~mm}$ in diameter. Argon was used as a protective gas. 
The wear resistance test was performed on the wear testing machine (As shown in Fig.2). The length of the sample is $260 \mathrm{~mm}$, and the dual part is 45 steel coupling. The medium is water and the load is $500 \mathrm{~N}$ with the speed of $40 \mathrm{r} / \mathrm{min}$ and the whole time of $120 \mathrm{~h}$. After laser surface melting, the weight loss was applied to evaluation of the wear resistance of laser melted layer. The cross-sections of the laser surface-melted specimens were polished and then etched with chloroazotic acid. Vickers microhardness measurements were performed using a load of $200 \mathrm{~g}$. The microstructure of the laser melted layer and the worn morphology were analyzed by scanning electron microscopy (SEM).

Table 1 Chemical composition of N80 tubing (mass fraction, \%)

\begin{tabular}{ccccccccccccc}
\hline $\mathrm{C}$ & $\mathrm{Si}$ & $\mathrm{Mn}$ & $\mathrm{P}$ & $\mathrm{S}$ & $\mathrm{Cr}$ & $\mathrm{Ni}$ & $\mathrm{Mo}$ & $\mathrm{Cu}$ & $\mathrm{Al}$ & $\mathrm{Ti}$ & $\mathrm{V}$ & $\mathrm{Fe}$ \\
\hline 0.32 & 0.32 & \multirow{2}{*}{1.52} & 0.011 & 0.006 & 0.07 & 0.03 & 0.024 & 0.096 & 0.011 & 0.004 & 0.127 & $\mathrm{Bal}$ \\
\hline
\end{tabular}

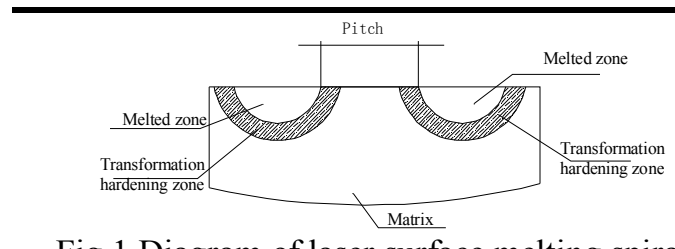

Fig.1 Diagram of laser surface melting spirally

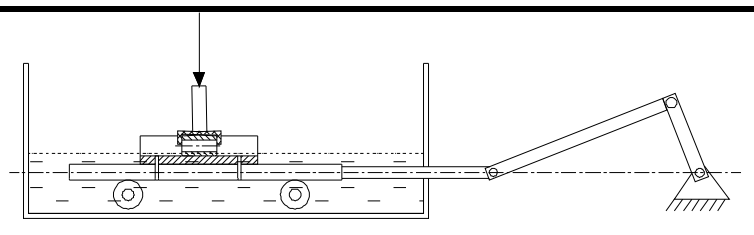

Fig.2 Diagram of wear testing setup

\section{Results and Discussion}

\section{Microstructure}

The microstructure of N80 oil tubing is uneven, and the zonal distribution characteristic is described along the cross section, which is composed of pearlite and ferrite (As shown in Fig.3a).

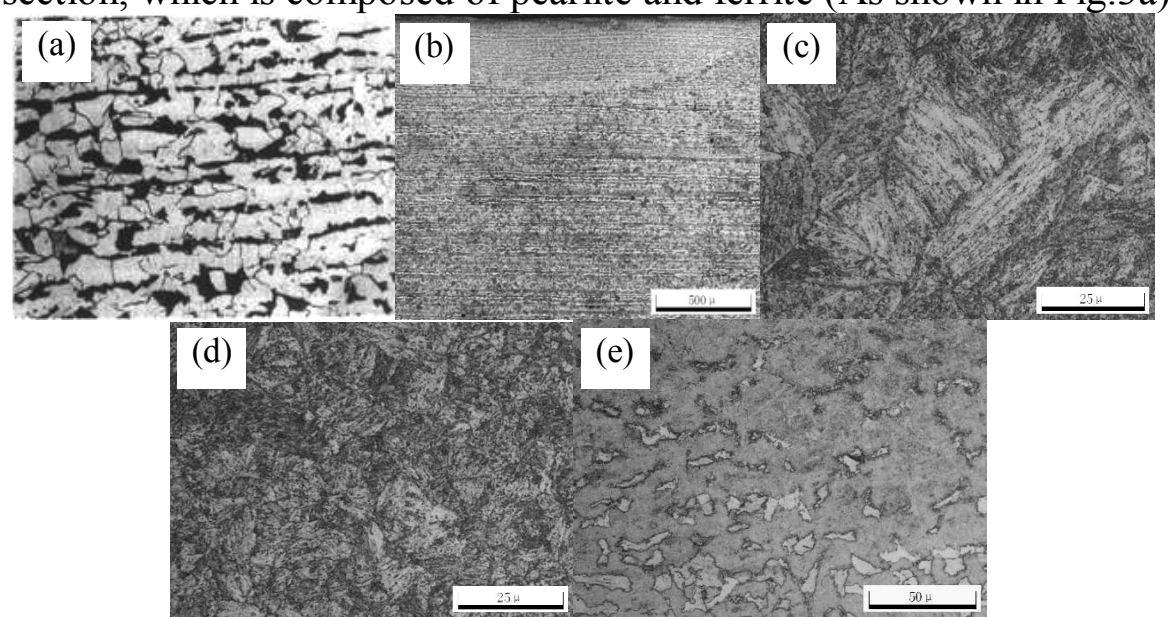

Fig.3 Microstructures of laser melted N80 oil tubing.

(a) N80 oil tubing;(b) cross section (c) laser melted zone (d) transformation hardening zone (e) high tempering zone

After laser surface melting, the cross section is divided into four zones: meted zone, transformation hardening zone, high temperature tempering zone and the matrix. The laser melted zone is composed of lath martensite and residual austenite (As shown in Fig.3b). As we know, the surface was heated rapidly with high temperature gradient as well as the peak temperature, which led to the growth of grain and relative large grain size. Then the sample is cooled depending on the heat conduction of the matrix when the laser beam left. As shown in Fig.3c, adjacent martensite distributes parallel, and the parallel martensite forms a martensitic field. In addition, one original grain consists of some martensitic fields, which resulted from the constant phase relationship between the martensite and austenite. Furthermore, the transformation hardening zone is composed of refined acicular martensite and residual austenite. In this area, the temperature reaches $A c_{1}-A c_{3}$, and there's not enough time grow up for the austenite grain. Therefore, refined acicular martensite was formed in the transformation hardening zone (As shown in Fig.3d). Additionally, the microstructure of the high temperature tempering zone is similar to the matrix, composed of pearlite and ferrite, but the zonal distribution characteristic disappears (Fig.3e). 
Microhardness analysis

Fig. 4 shows the hardness distribution of N80 oil tubing after LSM. The microhardness in laser meted zone and transformation hardening zone is much higher than of the matrix, which is resulted from the microstructure induced by rapid heating and cooling. With the increase of distance from the surface, the energy absorbed by the matrix decreases gradually, and the refined martensitic structure generated, which leads to the highest hardness in transformation hardening zone.

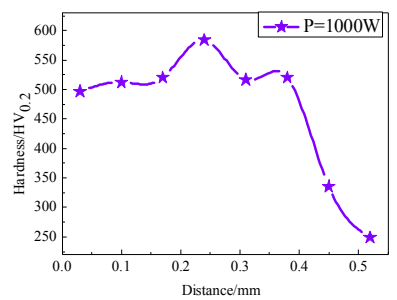

Wear resistance

Fig.4 Hardness distribution of N80 oil tubing by LSM

We can see from Fig.5 that the weight losses of N80 oil tubing and the coupling increase with the prolonged testing time. After wearing $120 \mathrm{~h}$, the maximum weight loss is up to $5.31 \mathrm{~g}$, and that of the coupling reaches $1.98 \mathrm{~g}$. Weight-loss curves of laser melted oil tubing with different pitches are shown in Fig.6. As it is can be seen, the weight loss with large pitch is higher than that of the small pitch. And the maximum weight loss with $12 \mathrm{~mm}$ pitch reaches $3.5 \mathrm{~g}$, while that of the oil tubing with $6 \mathrm{~mm}$ pitch only is $2.7 \mathrm{~g}$. That is, laser surface melting is helpful to improve the wear resistance.
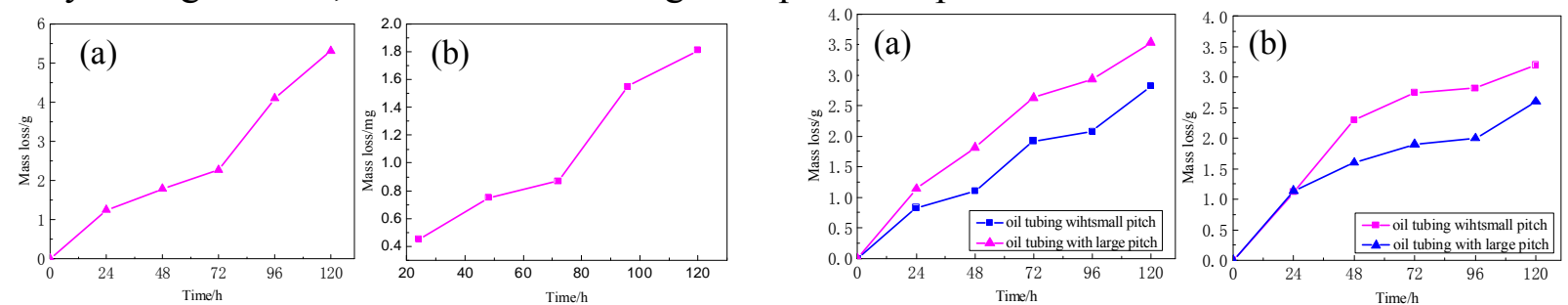

Fig.5 Weight-loss curves (a) oil tubing; (b) coupling Fig.6 Weight loss curves (a) laser melted N80 (b) coupling

According to Fig.7, serious wear occurred on the surface of oil tubing with the deep plough. For the laser melted oil tubing, spalling appeared in the untreated area, while the surface of laser melted region was smooth with fine wear scar. The uneven wear occurred on the inner wall of the N80 oil tubing, and a lot of plough and obvious spalling appeared (As shown in Fig.7b and Fig.7c). Therefore, the wear mechanism of N80 oil tubing is fatigue spalling. The hardness of N80 oil tubing is low. During wear process, the surface hardness is improved obviously due to the work hardening. In the subsurface the flaking cracks propagated parallel to the surface to form the lamellar spalled pits.
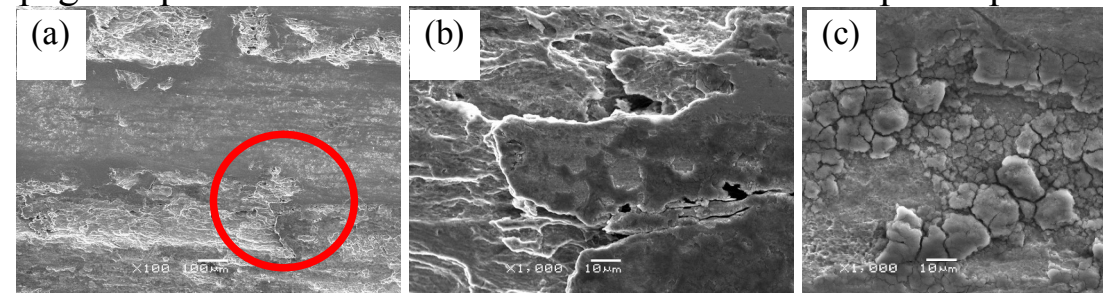

Fig.7 Wear morphologies of N80 oil tubing .macroscopic morphology (b) and (c) at high magnification

After laser surface melting the inner wall of N80 oil tubing is divided into two regions: laser melted zone (A) and untreated zone (B). As shown in Fig.8a, the wear stopped at the interface of the melted zone and the untreated zone. Especially obvious plastic deformation was generated at the interface (As shown in Fig.8b). The wear resistance of the laser melted zone is high, and the wear scars are fine (As shown in Fig. 8c). However, the wear mechanism of the untreated zone is same as the as-received N80 oil tubing (As shown in Fig.8d and Fig.7) with distinct fatigue spalling.

The microhardness of the laser melted N80 oil tubing is significantly improved due to refined microstructure and the martensitic structure. Furthermore, the working hardening resulting from the transformation from the residual austenite to the martensite under high stress condition contributes to the improvement of the hardness. On the other hand, the transformation hardening zone with high 
microhardness plays a role of supporting the laser melted zone. Thus, during wear process, the formation of cracks in the transformation hardening zone as well as the propagation is difficult, leading to the improvement of the wear resistance.

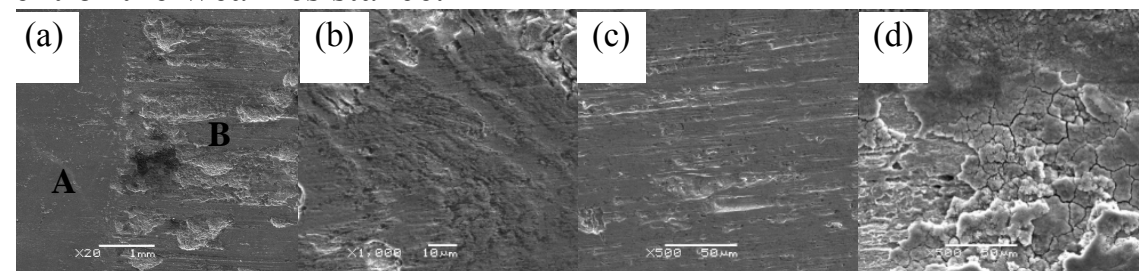

Fig.8 Wear morphologies. (a) macroscopic pattern (b) interface (c) laser melted zone (d) untreated zone

\section{Conclusions}

The microstructure of $\mathrm{N} 80$ oil tubing consists of zonal pearlite and ferrite. After LSM, the cross section was divided into the melted zone, transformation hardening zone, high temperature tempering zone and the matrix. The melted zone is composed of martensite, where the microhardness was improved, but the maximum appeared in the transformation hardening zone. The uneven wear phenomenon occurred on the inner wall of the N80 oil tubing, and a lot of plough and obvious spalling appeared. And the wear mechanism of the as-received N80 oil tubing is fatigue spalling. In addition, the wear resistance of laser melted N80 oil tubing was improved obviously, especially which of the melted sample with small pitch is higher than the large pitch. The plastic deformation stopped at the interface of the melted zone and the untreated zone, and the wear scars are shallow.

\section{ACKNOWLEDGEMENT}

The authors would like to acknowledge the supports from the Natural Science Foundation of Shandong Province (ZR2014EEQ037).

\section{References}

[1] Yan Tingjun, Wang Kuisheng and Guo Liqian, et al, Study of Wear Test for Anti wear Coating Sucker Rod and Tubing String, J. Lubrication Engineering. 4 (2004) 46-48.

[2] Eduardo P C, The use of selective plasma nitriding on piston rings for performance improvement, J. Materials\&Design. 24 (2003) 131-135.

[3] J.H.Abboud, K.Y.Benyounis, A.G.Olabi, et al, Laser surface treatments of iron-based substrates for automotive application, J. Journal of Materials Processing Technology. 182 (2007) 427-431.

[4] C.T.Kwok, F.T.Cheng,H. C. Man, Microstructure and corrosion behaviour of laser surface-melted high-speed steels, J. Surface\& Coatings Technology. 202 (2007) 336-348.

[5] Yu.Ivanov,W.Matz,V.Rotshtein, et al, Pulsed electron-beam melting of high-speed steel:structural phase transformations and wear resistance, J. Surface\&Coatings Technology. 150 (2002) 188-198.

[6] Zhang Fenggang, Zhu Xiaopeng, Wang Mingyang, et al, Surface modification of WC-Ni cemented carbide for seals by high-intensity pulsed ion beam irradiation, J. Acta Metallurgica Sinica. 47 (2011) 958-964.

[7] X.X.Mei, W.F.Sun,S.Z.Hao, et al, Surface modification of high-speed steel by intense pulsed ion beam irradiation, J. Surface\&Coatings Technology. 201 (2007) 5072-5076.

[8] R. Colaco, R.Vilar, Effect of laser surface melting on the tempering behaviour of din X42Cr13 stainless tool steel, J. Scripta Materialia. 38 (1997) 107-113.

[9] S. Kac,J.Kusinski, SEM structure and properties of ASP2060 steel after laser melting, J. Surface\&Coatings Technology. 180 (2004) 611-615. 